\title{
Biological Control of Rhizoctonia Root Rot on Bean by Phenazine- and Cyclic Lipopeptide-Producing Pseudomonas CMR12a
}

\author{
Jolien D’aes, Gia Khuong Hoang Hua, Katrien De Maeyer, Joke Pannecoucque, Ilse Forrez, Marc Ongena, \\ Lars E. P. Dietrich, Linda S. Thomashow, Dmitri V. Mavrodi, and Monica Höfte
}

First, second, third, fourth, and tenth authors: Laboratory of Phytopathology, Faculty of Bioscience Engineering, and fifth author: Laboratory of Microbial Ecology and Technology, Faculty of Bioscience Engineering, Ghent University, Coupure Links, 653, B-9000 Gent, Belgium; sixth author: Gembloux Agro-Bio Tech, University of Liege, Passage des Déportés, 2, B-5030 Gembloux, Belgium; seventh author: Department of Biological Sciences, Fairchild Center, 1108, Columbia University, New York 10027; eighth author: USDA-ARS, Root Disease and Biological Control Research Unit, Washington State University, Pullman 99164-6430; and ninth author: Department of Plant Pathology, Washington State University, Johnson Hall, 365, Pullman 99164-6430.

Accepted for publication 3 March 2011.

\begin{abstract}
D'aes, J., Hua, G. K. H., De Maeyer, K., Pannecoucque, J., Forrez, I., Ongena, M., Dietrich, L. E. P., Thomashow, L. S., Mavrodi, D. V., and Höfte, M. 2011. Biological control of Rhizoctonia root rot on bean by phenazine- and cyclic lipopeptide-producing Pseudomonas CMR12a. Phytopathology 101:996-1004.

Pseudomonas CMR12a was previously selected as an efficient biocontrol strain producing phenazines and cyclic lipopeptides (CLPs). In this study, biocontrol capacity of Pseudomonas CMR12a against Rhizoctonia root rot of bean and the involvement of phenazines and CLPs in this ability were tested. Two different anastomosis groups (AGs) of Rhizoctonia solani, the intermediately aggressive AG 2-2 and the highly aggressive AG 4 HGI, were included in growth-chamber experiments with bean plants. The wild-type strain CMR12a dramatically reduced

disease severity caused by both $R$. solani AGs. A CLP-deficient and a phenazine-deficient mutant of CMR12a still protected bean plants, albeit to a lesser extent compared with the wild type. Two mutants deficient in both phenazine and CLP production completely lost their biocontrol activity. Disease-suppressive capacity of CMR12a decreased after washing bacteria before application to soil and thereby removing metabolites produced during growth on plate. In addition, microscopic observations revealed pronounced branching of hyphal tips of both $R$. solani AGs in the presence of CMR12a. More branched and denser mycelium was also observed for the phenazine-deficient mutant; however, neither the CLP-deficient mutant nor the mutants deficient in both CLPs and phenazines influenced hyphal growth. Together, results demonstrate the involvement of phenazines and CLPs during Pseudomonas CMR12amediated biocontrol of Rhizoctonia root rot of bean.
\end{abstract}

Rhizoctonia solani (teleomorph: Thanatephorus cucumeris) is a soilborne pathogen causing severe damage to a wide range of crops. To date, this fungal species is subdivided into 13 different anastomosis groups (AGs) which may possess similar characteristics, such as host preference, pathogenicity, and type of disease symptom caused (7). In the production of common bean (Phaseolus vulgaris), root rot caused by $R$. solani is a major constraint leading to severe crop losses, especially under tropical and subtropical climate conditions. Several AGs of $R$. solani have been identified causing root rot on bean, the most frequently reported being AG 2-2 and AG $4(2,32,34)$. Knowledge about the prevalence and distribution of different AGs is important, because sensitivity to chemical control treatments and, probably, also to other control strategies varies among AGs $(6,27)$.

Beneficial bacteria have been intensively studied as biocontrol agents against soilborne diseases $(20,57)$. Good results have been obtained with gram-positive Bacillus spp. and gram-negative Pseudomonas spp. in the control of several plant pathogens, including Gaeumannomyces graminis var. tritici, Fusarium spp., and Pythium spp. $(18,29,58)$. In the case of $R$. solani, studies with different bacterial strains indicated that the biocontrol mechanism can be either induction of systemic resistance or antibiosis (24, 33). Among the great variety of beneficial bacteria and antibiotic

Corresponding author: M. Höfte; E-mail address: monica.hofte@ugent.be

doi:10.1094/PHYTO-11-10-0315

(c) 2011 The American Phytopathological Society metabolites already discovered, our attention has been focused on phenazines and biosurfactants produced by fluorescent pseudomonads.

Phenazines are broad-spectrum, heterocyclic antibiotics known for their antifungal properties. The most commonly identified phenazine pigments produced by Pseudomonas spp. are pyocyanin, phenazine-1-carboxylic acid (PCA), phenazine-1-carboxamide (PCN), and a number of hydroxy-phenazines (56). Production of phenazines is essential for the biocontrol capacity of Pseudomonas fluorescens 2-79 (52), P. chlororaphis PCL1391 (8), and $P$. aeruginosa PNA1 (51). In the biological control of $R$. solani, only a few reports suggest the involvement of phenazines. Rosales et al. (45) observed in vitro inhibition of mycelial growth of $R$. solani by $P$. aeruginosa strains which produced PCA and pyocyanin, while disease suppression of Rhizoctonia root rot of wheat in vivo was enhanced after transformation of $P$. fluorescens Q8r1-96 with the biosynthesis genes for PCA (25). However, conclusive evidence for the importance of phenazines in the biological control of Rhizoctonia diseases using phenazine-negative mutants is still lacking.

Biosurfactants are amphiphilic compounds possessing both hydrophilic and lipophilic properties. These surface-active metabolites can be produced by several Pseudomonas spp.; the most interesting ones include rhamnolipids and several types of cyclic lipopeptides (CLPs), both of which may possess antifungal properties $(43,44,50)$. Biocontrol-related research on biosurfactants has predominantly focused on the control of zoosporeproducing plant pathogens, such as Pythium and Phytophthora spp., in which case the mode of action resides in zoospore lysis 
$(12,15,50)$. Only a few studies have demonstrated the involvement of biosurfactants in biological control of non-zoospore-producing plant pathogens. A direct effect of biosurfactants on mycelium of Pythium myriotylum and $P$. splendens was hypothesized by Perneel et al. (39), while Debode et al. (10) found a major role for biosurfactants in the reduction of Verticillium microsclerotia viability. In vitro and in soil microcosm, antifungal properties of biosurfactants against $R$. solani have been described for the CLPs viscosinamide, tensin, and amphisin $(1,35,37,53)$. However, no literature reports were found which proved a crucial role for CLPs in disease suppression of $R$. solani in planta.

In the present study, we investigated the potential of Pseudomonas CMR12a to reduce Rhizoctonia root rot of bean caused by two different AGs of $R$. solani, AG 2-2 and AG 4 HGI. Pseudomonas CMR12a, which produces both CLP-type biosurfactants and the phenazines PCN and PCA, is a promising biocontrol strain previously isolated from the cocoyam rhizosphere in Cameroon (40). Analysis of $16 \mathrm{~S}$ rDNA sequences and phenazine biosynthesis genes indicated that CMR12a probably represents a novel species within the Pseudomonas putida species complex $(30,40)$. Mutants of CMR12a deficient in CLP or phenazine production were used to investigate the role of both compounds in disease suppression of Rhizoctonia root rot on bean.

\section{MATERIALS AND METHODS}

Microorganisms and culture conditions. Microorganisms used in this study are listed in Table 1. R. solani isolates were maintained on potato dextrose agar (PDA) (Difco Laboratories, Detroit) plates at $28^{\circ} \mathrm{C}$. Pseudomonas strains were routinely grown on King's medium B (KB) $(28)$ at $28^{\circ} \mathrm{C}$. Escherichia coli strains were grown on Luria-Bertani medium (LB) (46) at $37^{\circ} \mathrm{C}$, and Saccharomyces cerevisiae on yeast-extract-peptone-dextrose at $30^{\circ} \mathrm{C}$ (49). When required, gentamicin was added at a concentration of $25 \mu \mathrm{g} \mathrm{ml}^{-1}$ for E. coli strains and at $300 \mu \mathrm{g} \mathrm{ml}^{-1}$ for Pseudomonas CMR12a and mutant strains.
Construction of vectors and CMR12a mutant strains. Molecular techniques were performed according to standard methods (46). Taq DNA polymerase and Q-solution were purchased from Qiagen (Venlo, The Netherlands) and polymerase chain reaction (PCR) was carried out as recommended by the manufacturer. Plasmids and primers are listed in Table 1.

Construction of pMQ30- $\triangle P h z$ and mutant CMR12a- $\Delta P h z$. To construct mutant CMR12a- $\triangle \mathrm{Phz}$, the complete phenazine biosynthesis operon phzABCDEFGH (14) was deleted, using allelic replacement vector pMQ30, as described by Shanks et al. (49) and Hoang et al. (23). Two regions upstream and downstream of the phenazine biosynthesis operon phzABCDEFGH of CMR12a were amplified with primers PhzA-Up-F and PhzA-Up-R (856 bp) and primers PhzH-Down-F and PhzH-Down-R (904 bp), respectively. These PCR products were cloned flanking each other via in vivo homologous recombination in the yeast $S$. cerevisiae InvSc1. This procedure yielded deletion plasmid pMQ30- $\Delta \mathrm{Phz}$, which was mobilized into CMR12a by conjugation with $E$. coli BW29427 and selection on gentamicin. Transconjugants which had lost the plasmid during a second crossover event were selected on $10 \%$ sucrose, whereupon the deletion was confirmed by PCR.

Cloning of CLP biosynthesis genes of CMR12a. To track down the genes responsible for biosurfactant synthesis in CMR12a, a transposon mutant library, constructed by mating with $E$. coli SM10 carrying pUT-miniTn5phoA3 (11), was screened for mutants with reduced surface activity on KB medium by means of a drop-collapse test (26). In one of these biosurfactant-deficient mutants, the transposon interrupted an open reading frame showing homology with nonribosomal peptide synthetase (NRPS) genes responsible for CLP synthesis in other pseudomonads. This sequence was used as a probe for screening a pRG930 cosmid genomic library of CMR12a (14). Primer walking on positive clone 24G3 yielded a 1.9-kb DNA fragment, which was used to create a site-specific CLP mutant in CMR12a.

Construction of pEX18Tc-CLP1 and mutants CMR12a-CLP1 and CMR12a- $\triangle P h z-C L P 1$. CLP insertion mutants CMR12a-CLP1

TABLE 1. Microorganisms, plasmids, and primers used in this study

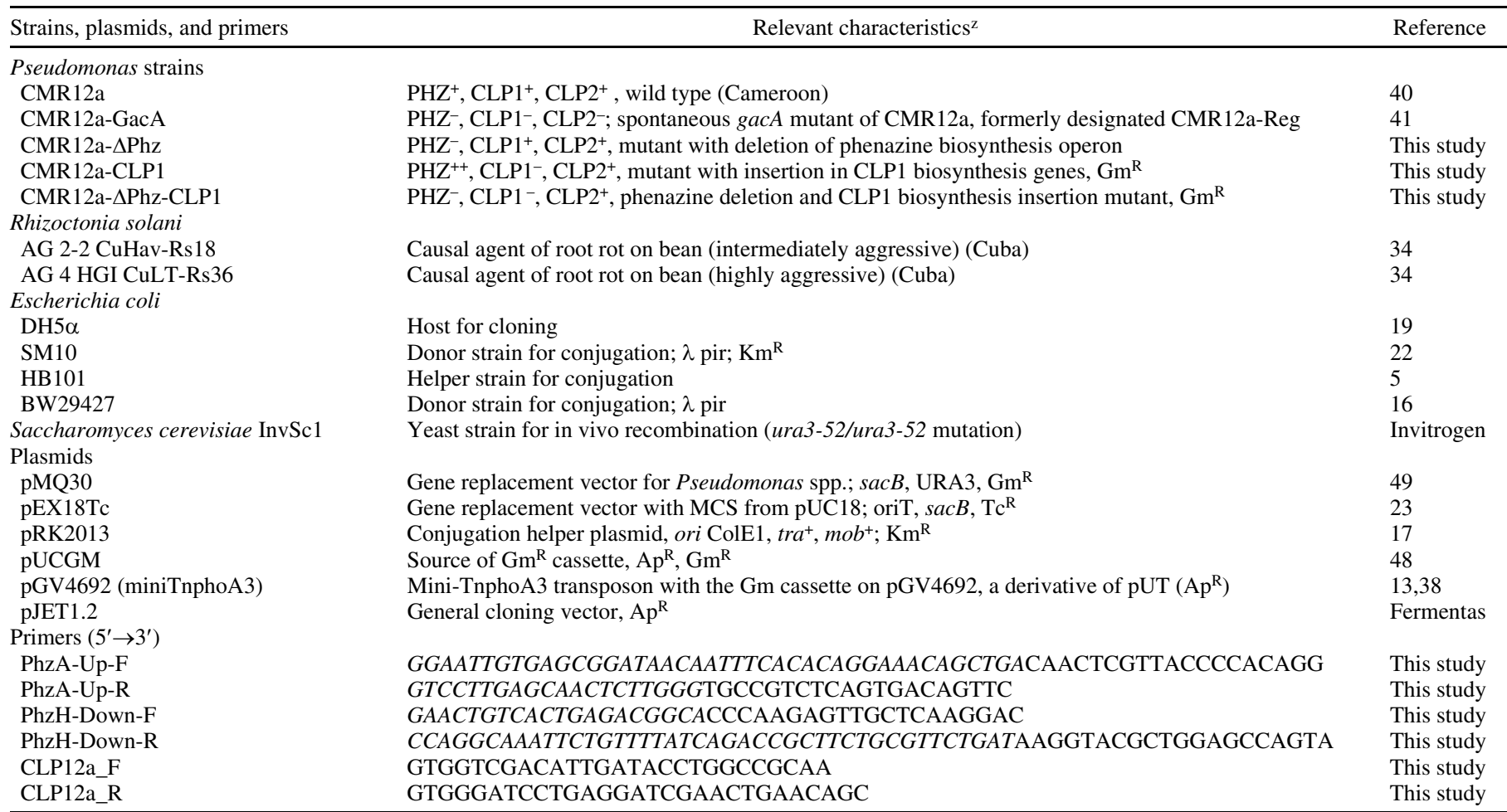

${ }^{\mathrm{z}}$ PHZ, phenazines; CLP, cyclic lipopeptides; +, positive for trait (similar to wild type [WT]), ++, overproduction compared with WT, -, negative for trait; Gm ${ }^{\mathrm{R}}$, $\mathrm{Tc}^{\mathrm{R}}, \mathrm{Amp}^{\mathrm{R}}$, and $\mathrm{Km}^{\mathrm{R}}$ = resistant to gentamicin, tetracyclin, ampicillin, and kanamycin, respectively. Primer extensions are in italic font. 
and CMR12a- $\triangle \mathrm{Phz}-\mathrm{CLP1}$ were constructed using vector $\mathrm{pEX} 18 \mathrm{Tc}$ (23). A 1.8-kb fragment of an NRPS, presumably coding for biosurfactant biosynthesis in CMR12a (see above), was amplified with primers CLP12a_F and CLP12a_R. The resulting PCR product was cloned in pEX18Gm and cut with SalI and BamHI to insert a gentamicin-resistance cassette from pUCGM (48). Following mobilization of the resulting plasmid (pEX18Tc-CLP1) into CMR12a and CMR12a- $\Delta \mathrm{Phz}$, transconjugants which lost the suicide plasmid after a second cross-over event were selected on LB with 5\% sucrose. The gentamicin-resistance insertion was confirmed by PCR.

Analysis of phenazine and CLP production. Phenazines were extracted and analyzed by thin-layer chromatography and highpressure liquid chromatography (HPLC) as described before (39, $41)$. To obtain quantitative data for phenazine production, spectrophotometric measurements $\left(\lambda=369 \mathrm{~nm}\right.$ and $\left.\varepsilon=11,393 \mathrm{M}^{-1} \mathrm{~cm}^{-1}\right)$ were performed on supernatant of bacterial cultures grown for $16 \mathrm{~h}$ in LB broth. An estimation of the extinction coefficient was derived from a standard curve for unsubstituted phenazine (SigmaAldrich, St. Louis), dissolved in water at different concentrations.

The presence of surface-active compounds was tested by the drop-collapse technique (26). Surface tension was measured as described by Perneel et al. (40) with minor modifications. Strains were grown on KB medium for $72 \mathrm{~h}$, whereupon cells were scraped from the plates and suspended in sterile distilled water, and cell concentrations were estimated by measuring optical density at $620 \mathrm{~nm}\left(\mathrm{OD}_{620}\right)$. After centrifugation of the suspensions, surface tension of cell-free supernatants was measured with a tensiometer equipped with a Wilhelmy plate. For liquidchromatography mass-spectrometry (LC-MS) analysis, supernatant samples were collected after $72 \mathrm{~h}$ of growth on LB medium and subjected to reverse-phase LC-MS (HPLC Waters Alliance 2695/diode array detector, coupled with Waters SQD mass spectrometer) on an X-terra MS C18 column (100 by $4.6 \mathrm{~mm}$, $3.5 \mu \mathrm{m}$ ) (Waters). CLPs were eluted with a gradient of acetonitrile in water acidified with $0.1 \%$ formic acid at a constant flow rate of $0.5 \mathrm{ml} \mathrm{min}-1$ and $40^{\circ} \mathrm{C}$. Compounds were detected in the scan mode or SIR mode and in-source settings (electrospray ionization, positive ion) in the SQD were as follows: source temperature, $130^{\circ} \mathrm{C}$; desolvation temperature, $280^{\circ} \mathrm{C}$; nitrogen flow, 550 liters $\mathrm{h}^{-1}$; and cone voltage, 60 or $80 \mathrm{~V}$, depending on the compound. $\mathrm{HCN}$ and exoprotease production were determined as described before (40).

Plant material and bacterial application to soil. Plant experiments were carried out using bean seed of Phaseolus vulgaris 'Prelude' (Het Vlaams Zaadhuis, Waarschoot, Belgium). To reduce the variability in emergence, bean seed were pregerminated before sowing. Seed were surface sterilized in $1 \%$ sodium hypochlorite solution for $5 \mathrm{~min}$, rinsed twice in sterile distilled water, and placed in petri dishes on sterile moistened filter paper. After 3 days at room temperature, germinated seed were sown in perforated plastic trays ( 22 by 15 by $6 \mathrm{~cm}$ ) filled with $700 \mathrm{~g}$ of a mixture composed of 50\% sand and $50 \%$ nonsterile potting soil (wt/wt) (Structural; Snebbout, Kaprijke, Belgium). Bacterial inoculum suspensions were prepared by growing CMR12a and its mutants on $\mathrm{KB}$ agar plates for 24 to $28 \mathrm{~h}$. Bacterial cells were scraped from the plates and suspended in sterile saline $(0.85 \%$ $\mathrm{NaCl})$. Concentrations of bacterial suspensions were estimated based on their $\mathrm{OD}_{620}$. Washed bacteria were obtained by centrifuging bacterial suspensions twice for $4 \mathrm{~min}$ at 13,400 rpm and resuspending bacterial pellets in saline prior to determination of their $\mathrm{OD}_{620}$. The amount of suspension to be added to each tray was calculated and diluted to $50 \mathrm{ml}$ with saline. Prior to sowing, the sand/potting soil substrate was thoroughly mixed with the diluted bacterial inoculum to obtain a final concentration of $10^{6} \mathrm{CFU} \mathrm{g}^{-1}$ of soil.

Pathogen inoculation and disease rating. Inoculum of $R$. solani AG 2-2 and AG 4 HGI was produced on sterile wheat kernels according to the protocol described by Scholten et al. (47), with minor modifications. Water-soaked wheat kernels were autoclaved twice on two consecutive days and inoculated with three PDA discs (diameter $=5 \mathrm{~mm}$ ) cut at the margin of a 3-dayold Rhizoctonia colony. Inoculated wheat kernels were incubated at $28^{\circ} \mathrm{C}$ for 6 days for the highly aggressive $R$. solani AG 4 HGI and 9 days for the intermediately aggressive $R$. solani AG 2-2. Every 3 to 4 days, wheat kernels were shaken to avoid coagulation. Plastic trays containing bean seedlings were inoculated 3 days after sowing by placing a row of 40 infected wheat kernels in the middle of the tray at a depth of $\approx 2 \mathrm{~cm}$ and a distance of $3 \mathrm{~cm}$ from the bean seedlings. Six days after inoculation, disease symptoms were evaluated using the following scale: $0=$ healthy, absence of symptoms; $1=$ small black or brown lesions $<1 \mathrm{~mm}$ in diameter; $2=$ lesion covering $<75 \%$ of the stem or root surface; $3=$ lesion covering $>75 \%$ of the stem or root surface; and $4=$ seedling dead. All plant experiments were carried out in a growth chamber $\left(28^{\circ} \mathrm{C}, \approx 70 \%\right.$ relative humidity, 16-h photoperiod).

Each plant experiment consisted of three replications (trays) per treatment, with 10 bean plants per tray; and, in each experiment, healthy and infected control treatments were included, together with the bacterial treatments. All experiments were repeated in time.

Evaluation of root colonization by Pseudomonas CMR12a and its mutants. At the time of disease rating, bacterial colonization of the bean roots was determined. Roots of five plants per treatment, randomly chosen from the three different trays, were excised and rinsed under tap water to remove most of the soil. After weighing, roots were macerated in sterile saline using mortar and pestle and serial dilutions were plated on KB agar. Bacterial colonies showing the typical morphological characteristics of Pseudomonas CMR12a, and which do not appear on control plates, were counted after an incubation period of 36 to $48 \mathrm{~h}$ at $28^{\circ} \mathrm{C}$.

Data analysis. Statistical analysis of data was performed using the software package SPSS 15.0 for Windows (SPSS Inc., Chicago). Neither the ordinal data of the disease severity nor the data of the root colonization experiments met the conditions of normality and homogeneity of variances. As a consequence, nonparametric Kruskal-Wallis and Mann-Whitney comparisons ( $\alpha=0.05$ ) were performed.

Microscopic observations. Microscopic experiments were carried out based on a protocol described by Bolwerk et al. (4), with modifications. Bacterial strains were grown overnight in liquid $\mathrm{KB}$ at $28^{\circ} \mathrm{C}$ on a rotary shaker $(150 \mathrm{rpm})$. Microscopy slides were covered with a thin layer of water agar $(1.5 \%)$ and placed in petri dishes containing moistened filter paper. A 5-mm PDA plug of a 3-day-old $R$. solani colony was placed in the center of glass slide while a droplet $(15 \mu \mathrm{l})$ of the overnight culture of Pseudomonas CMR12a or mutant strain was pipetted at either side. The petri plates were sealed with parafilm and incubated for $36 \mathrm{~h}$ at $28^{\circ} \mathrm{C}$ before observation under light microscopy (Olympus BX51 microscope; Aartselaar, Belgium). Digital images were acquired using an Olympus Color View II camera and further processed with Olympus analySIS cell^ ${ }^{\wedge}$ software (Olympus Soft Imaging Solutions, Münster, Germany). All experiments were performed twice.

\section{RESULTS}

Characterization of Pseudomonas CMR12a and its mutants. HPLC analysis and UV absorption measurements of culture supernatant confirmed that both PCA and PCN production were abolished in mutants CMR12a- $\Delta \mathrm{Phz}$ and CMR12a- $\Delta \mathrm{Phz}-$ CLP1. Remarkably, CMR12a-CLP1 produced significantly higher amounts of phenazines than the wild type, an observation which cannot be accounted for at this point (Table 2). Various approaches, including reverse-phase LC-MS of CMR12a culture 
TABLE 2. Phenazine and cyclic lipopeptide (CLP) production by CMR12a and mutants ${ }^{\mathrm{u}}$

\begin{tabular}{|c|c|c|c|c|c|c|}
\hline \multirow[b]{3}{*}{ Strain } & \multicolumn{3}{|c|}{ Phenazines } & \multicolumn{3}{|c|}{ CLPs } \\
\hline & \multicolumn{2}{|c|}{$\mathrm{HPLC}^{\mathrm{v}}$} & \multirow[b]{2}{*}{ Phenazine $\left(\mu \mathrm{M} / \mathrm{OD}_{620}\right)^{\mathrm{y}}$} & \multicolumn{2}{|c|}{$\mathrm{HPLC}^{\mathrm{v}}$} & \multirow[b]{2}{*}{ Tension $(\mathrm{mN} / \mathrm{m})^{2}$} \\
\hline & $\mathrm{PCA}^{\mathrm{w}}$ & $\mathrm{PCN}^{\mathrm{x}}$ & & CLP1 & CLP2 & \\
\hline CMR12a & + & + & $33 \pm 3$ & + & + & $35 \pm 2$ \\
\hline CMR12a- $\Delta \mathrm{Phz}$ & - & - & $<\mathrm{DL}$ & + & + & $36 \pm 1$ \\
\hline CMR12a-CLP1 & + & ++ & $67 \pm 6$ & - & + & $47 \pm 5$ \\
\hline CMR12a- $\Delta$ Phz-CLP1 & - & - & $<\mathrm{DL}$ & - & + & $59 \pm 6$ \\
\hline CMR12a-GacA & - & - & $<\mathrm{DL}$ & - & - & $54 \pm 6$ \\
\hline
\end{tabular}

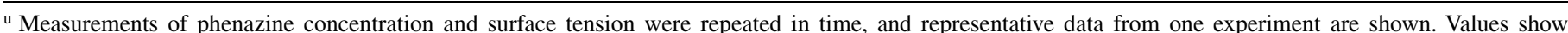
means and standard deviations of three independent replicates.

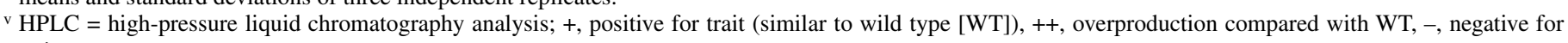
trait.

${ }^{\text {w } P C A}=$ phenazine-1-carboxylic acid.

x $\mathrm{PCN}=$ phenazine-1-carboxamide.

y Phenazine concentration in culture supernatant; $\mathrm{OD}_{620}=$ optical density at $620 \mathrm{~nm} ;<\mathrm{DL}=$ value below detection limit.

${ }^{\mathrm{z}}$ Surface tension of culture supernatant.

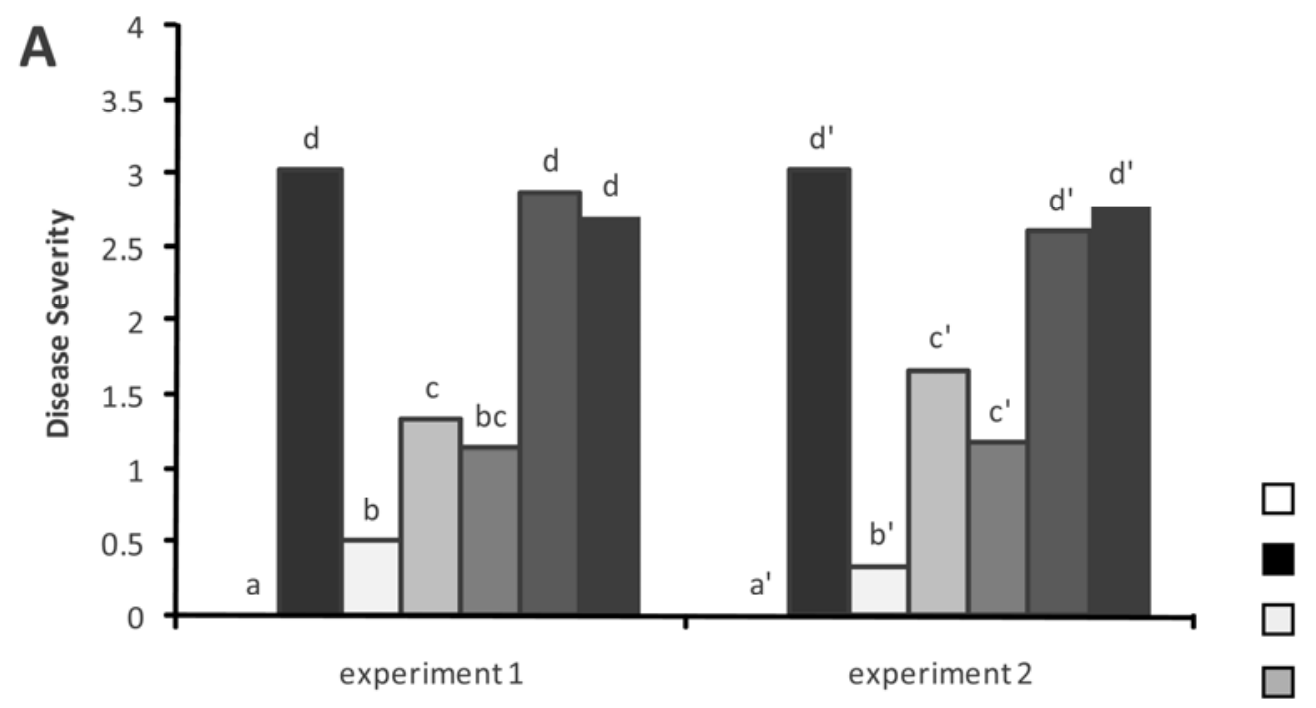

\section{Control}

R. solani

R. solani + CMR12a

R. solani + CMR12a- $\triangle \mathrm{Phz}$

R. solani + CMR12a-CLP1

B

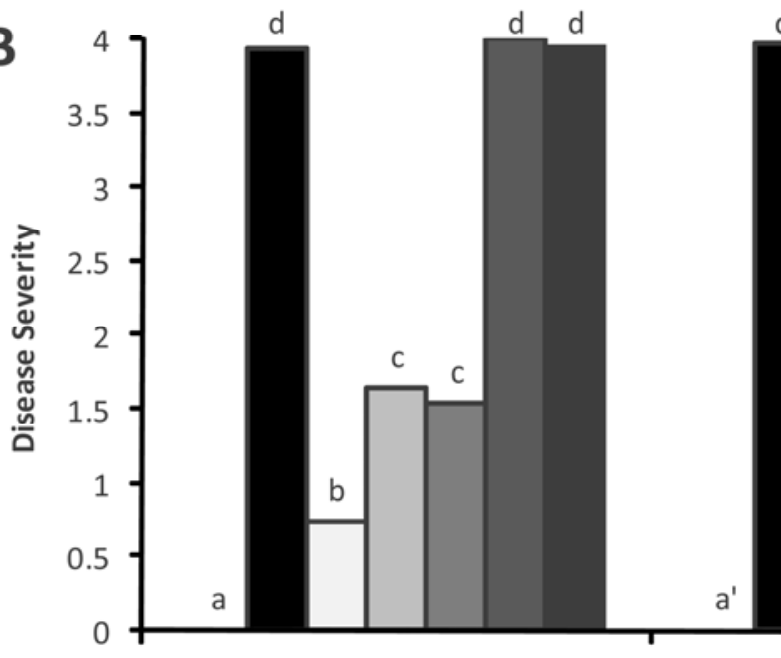

experiment 1

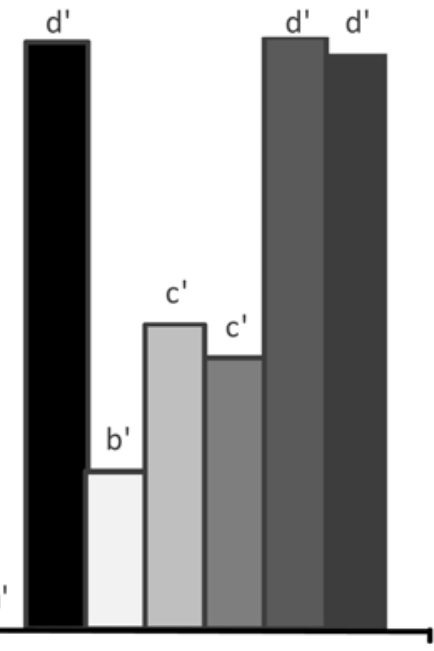

experiment 2

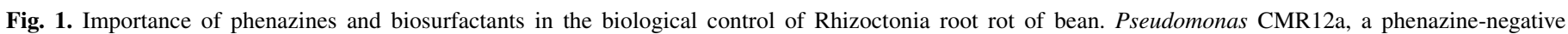

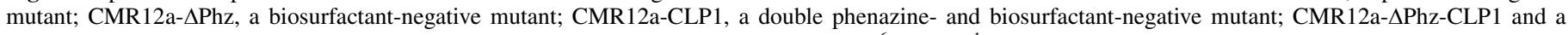

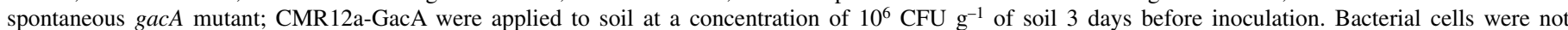

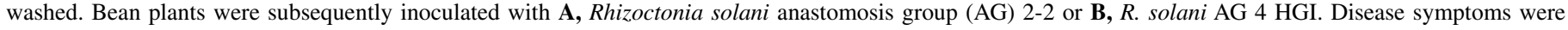

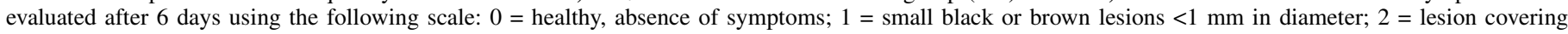

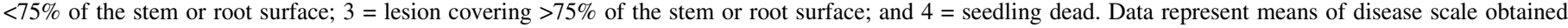

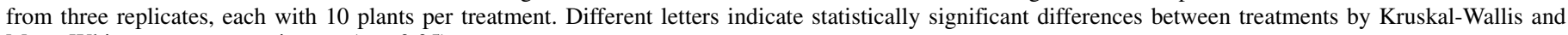
Mann-Whitney nonparametric tests $(\alpha=0.05)$. 
extracts and in silico analysis of genomic data, provided evidence that CMR12a synthesizes two types of CLPs (results not shown). For each CLP type, several presumably closely related variants seemed to be produced. For the main compound of the first CLP group, which has been designated CLP1, the detected molecular ion had a molecular weight of $\approx 2,028$ Da. Preliminary results indicated that this is a novel compound within the tolaasin group of CLPs (43). Production of CLP1 was completely abolished in mutants CMR12a-CLP1 and CMR12a- $\triangle P$ hz-CLP1. For the second CLP type (designated CLP2), three main compounds with molecular ions of 1,253, 1,279, and 1,281 Da were detected, which were all still being produced by both CLP mutants at wildtype levels. In CMR12a- $\Delta$ Phz, the pattern of CLP production was not altered compared with that of the wild type (results not shown). A more detailed structural characterization of both CLPs is in progress.

In addition to these biosynthesis mutants, a regulatory mutant, CMR12a-GacA (41) (Table 1), was also tested for its biocontrol ability against $R$. solani on bean. This mutant has a spontaneous mutation in the GacS/GacA two-component regulatory system (21). In CMR12a-GacA, not only phenazine production but also synthesis of other secondary metabolites, including exoproteases and $\mathrm{HCN}$ (results not shown), is abolished. In addition, neither CLP1 nor CLP2 production could be detected in supernatant extracts of CMR12a-GacA, indicating that GacA controls production of both lipopeptides.

Biocontrol of Rhizoctonia root rot of bean by Pseudomonas CMR12a and its phenazine or CLP mutants. We investigated whether Pseudomonas CMR12a could provide protection in vivo against Rhizoctonia root rot. In the experiments, four mutants of CMR12a deficient in phenazine or CLP production were included (Table 2). A significant reduction of disease severity (DS) caused by $R$. solani on bean plants was observed for the wild-type strain Pseudomonas CMR12a (Fig. 1). The numerical data described further are valid for repetition 1 (Fig. 1); repetition 2 yielded similar results. For the intermediately aggressive isolate of $R$. solani AG $2-2$, a reduction in DS from $\approx 3.1 \pm 0.9$ to $0.5 \pm 1.0$ was recorded $(P=0.000)$; for the very aggressive isolate of $R$. solani AG 4 HGI, which killed almost all plants in the control treatment,

TABLE 3. Root colonization data for nonwashed bacteria of Pseudomonas CMR12a and mutants CMR12a- $\Delta$ Phz, CMR12a-CLP1, CMR12a- $\Delta$ PhzCLP1, and CMR12a-GacA in the absence of Rhizoctonia solani or after inoculation with $R$. solani anastomosis group (AG) 2-2 or $R$. solani AG $4 \mathrm{HGI}^{\mathrm{z}}$

\begin{tabular}{|c|c|c|}
\hline \multirow[b]{2}{*}{ Treatment } & \multicolumn{2}{|c|}{$\begin{array}{c}\text { Bacterial population } \\
\text { (in } \log \text { CFU g } \text { g }^{-1} \text { of fresh root) }\end{array}$} \\
\hline & Repetition 1 & Repetition 2 \\
\hline \multicolumn{3}{|l|}{ Without $R$. solani } \\
\hline CMR12a & $6.14 \pm 0.37 \mathrm{a}$ & $5.61 \pm 0.46 \mathrm{c}$ \\
\hline CMR12a- $\Delta \mathrm{Phz}$ & $5.81 \pm 0.47 \mathrm{~b}$ & $6.95 \pm 0.30 \mathrm{a}$ \\
\hline CMR12a-CLP1 & $5.14 \pm 0.34 \mathrm{c}$ & $6.00 \pm 0.39 \mathrm{~b}$ \\
\hline CMR12a- $\Delta$ Phz-CLP1 & $5.22 \pm 0.35 \mathrm{c}$ & $5.27 \pm 0.39 \mathrm{~d}$ \\
\hline CMR12a-GacA & $5.02 \pm 0.47 \mathrm{c}$ & $4.75 \pm 0.36 \mathrm{e}$ \\
\hline \multicolumn{3}{|l|}{ R. solani AG 2-2 } \\
\hline CMR12a & $6.53 \pm 0.31 \mathrm{a}$ & $6.03 \pm 0.36 \mathrm{~b}$ \\
\hline CMR12a- $\Delta \mathrm{Phz}$ & $5.86 \pm 0.71 \mathrm{bc}$ & $6.62 \pm 0.28 \mathrm{a}$ \\
\hline CMR12a-CLP1 & $6.07 \pm 0.53 \mathrm{~b}$ & $6.68 \pm 0.57 \mathrm{a}$ \\
\hline CMR12a- $\Delta$ Phz-CLP1 & $5.40 \pm 0.30 \mathrm{c}$ & $5.30 \pm 0.29 \mathrm{c}$ \\
\hline CMR12a-GacA & $5.38 \pm 0.31 \mathrm{c}$ & $4.92 \pm 0.37 \mathrm{~d}$ \\
\hline \multicolumn{3}{|l|}{ R. solani AG 4 HGI } \\
\hline CMR12a & $6.38 \pm 0.44 \mathrm{a}$ & $5.34 \pm 0.33 \mathrm{~cd}$ \\
\hline CMR12a- $\Delta \mathrm{Phz}$ & $6.14 \pm 0.79 \mathrm{ab}$ & $7.39 \pm 0.24 \mathrm{a}$ \\
\hline CMR12a-CLP1 & $6.55 \pm 0.45 \mathrm{a}$ & $6.84 \pm 0.37 b$ \\
\hline CMR12a- $\Delta$ Phz-CLP1 & $5.18 \pm 0.44 \mathrm{c}$ & $5.56 \pm 0.34 \mathrm{c}$ \\
\hline CMR12a-GacA & $5.68 \pm 0.32 b$ & $5.16 \pm 0.38 \mathrm{~d}$ \\
\hline
\end{tabular}

${ }^{\mathrm{z}}$ Data represent means and standard deviations of five replicates per treatment. Different letters indicate statistically significant differences between treatments by Kruskal-Wallis and Mann-Whitney nonparametric tests $(\alpha=$ $0.05)$. a decrease in DS from $\approx 3.9 \pm 0.3$ to $0.7 \pm 1.2$ was observed $(P=$ $0.000)$. Treatments with the mutant strains performed significantly worse. Mutants CMR12a- $\Delta \mathrm{Phz}$ and CMR12a-CLP1 were still able to reduce the DS caused by both AGs of $R$. solani, although to a lower extent than the wild type. On the other hand, mutants which are deficient in both phenazine and CLP production, biosynthesis mutant CMR12a- $\triangle \mathrm{Phz}-\mathrm{CLP} 1$ and gacAmutant CMR12a-GacA, completely lost their biocontrol capacity, and the DS for these strains was not statistically different from the diseased control.

Bacterial counts revealed differences in bacterial populations on the roots (Table 3). Bacterial concentrations observed for the parental strain and the mutants CMR12a- $\Delta \mathrm{Phz}$ and CMR12aCLP1 were variable among treatments and repetitions in time. However, this did not influence the disease-suppressive capacity, suggesting that root colonization was at a sufficiently high level for optimal biological control. The two mutants CMR12a- $\Delta$ PhzCLP1 and CMR12a-GacA, lacking both phenazine and CLP production, predominantly had the lowest bacterial root concentrations and in only one experiment were their root concentrations not significantly lower compared with the wild type. CMR12a bacteria were never recovered from roots of noninoculated control plants. Moreover, application of CMR12a or its mutants to the soil never caused visible phytotoxic effects or effects on plant growth, as observed by qualitative inspection of the plants.

Biocontrol capacity of washed CMR12a bacteria and its mutants. To investigate whether metabolites produced during growth of bacterial strains on $\mathrm{KB}$ agar plates are involved in the biocontrol capacity of Pseudomonas CMR12a, bacteria were washed before application to the sand/potting soil mixture (Fig. 2 ). The reduction in DS upon treatment with washed bacteria was smaller compared with the nonwashed bacteria. For the plants inoculated with the washed wild-type strain, DS caused by $R$. solani AG 2-2 was reduced from $3.8 \pm 0.8$ (first repetition) and $2.8 \pm 1.0$ (second repetition) to $\approx 1.5 \pm 1.1$. Treatment with the washed mutant strains CMR12a- $\Delta \mathrm{Phz}$ and CMR12a-CLP1 resulted in a DS reduction intermediate between the diseased control and the reduction caused by the wild-type strain (DS $=2.6 \pm 1.5$ in repetition 1 and $\mathrm{DS}=2.0 \pm 1.2$ in repetition 2 ), whereas mutants CMR12a- $\triangle$ Phz-CLP1 and CMR12a-GacA did not influence the disease development and DS was not statistically different from the diseased control.

In contrast to the disease reduction of almost $50 \%$ observed for $R$. solani AG 2-2, washed bacteria only had a minor effect on the disease caused by the very aggressive isolate of $R$. solani AG 4 HGI. The wild-type strain and the mutants CMR12a- $\Delta \mathrm{Phz}$ and CMR12a-CLP1 still reduced the DS significantly, from $4.0 \pm 0.0$ to $\approx 3.5 \pm 0.6$. The two other mutants did not differ from the diseased control and, at the time of evaluation, all plants were dead. The washing step did not influence root colonization, because bacterial counts after the application of washed bacteria were at a level comparable with those for the nonwashed bacteria. In the first repetition, CMR12a bacteria were recovered at a concentration of $5.57 \pm 0.31 \log \mathrm{CFU} \mathrm{\textrm {g } ^ { - 1 }}$ of fresh root after inoculation with $R$. solani AG 2-2 and at $5.58 \pm 0.41 \log \mathrm{CFU} \mathrm{g}^{-1}$ of fresh root after inoculation with $R$. solani AG $4 \mathrm{HGI}$; in the second repetition, bacterial densities were slightly higher, with

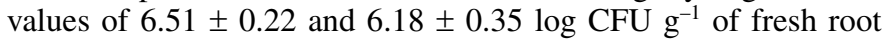
for AG 2-2 and AG 4 HGI, respectively.

Microscopic observations. $R$. solani hyphae in the presence of bacterial cells were examined with a light microscope to study changes in the growth pattern. At the contact zone between the mycelium of $R$. solani grown on coated microscopic glass slides and the bacterial droplets, morphological differences were observed (Fig. 3). The mycelium of $R$. solani AG 2-2 and AG 4 HGI was more branched in the presence of CMR12a and CMR12a$\triangle \mathrm{Phz}$ bacteria, resulting in a higher density of hyphae. In contrast, the three other mutants (e.g., CMR12a-CLP1, CMR12a- $\Delta$ Phz- 
CLP1, and CMR12a-GacA) did not induce an increase in hyphal branching, and $R$. solani hyphae of both AGs showed similar morphology compared with the control hyphae grown in the absence of bacteria.

\section{DISCUSSION}

Inhibition zones between hyphae of $R$. solani and Pseudomonas CMR12a cells were observed during preliminary in vitro dual culture experiments, suggesting a strong antagonistic potential of this bacterial strain toward $R$. solani. In this study, we showed that CMR12a effectively controls Rhizoctonia root rot of bean caused by $R$. solani AG 2-2 or $R$. solani AG 4 HGI. Moreover, the importance of CLP and phenazine production for the diseasesuppressive effect of CMR12a was clearly demonstrated. It is unclear whether these effects are due to direct antibiotic activity of CLPs and phenazines. Alternatively, one or both compounds may somehow be involved in the ecological fitness of CMR12a, thus indirectly influencing the biocontrol capacity of CMR12a.

Direct antibiosis of CLPs is likely to be involved because microscopic experiments clearly showed an increase in hyphal branching of $R$. solani AG 2-2 and AG 4 HGI caused by CMR12a whereas a normal growth pattern was observed with the CLPdeficient mutant CMR12a-CLP1. In addition, an in vitro growth assay with both wild-type CMR12a and the CLP1 mutant indicated a strong inhibitory effect of these CLPs on $R$. solani growth (unpublished data). Extensive branching of $R$. solani hyphae was previously observed after treatment with the structurally related CLPs viscosinamide and tensin. The authors assumed that viscosinamide imposes ion channels in the membranes, leading to an increased $\mathrm{Ca}^{2+}$ influx and morphological changes of the hyphae (54). In the case of tensin, however, an alternative mode of action was suggested, possibly involving interference with cell wall synthesis (37). Phenazines also exert direct antibiotic effects toward several plant pathogens, including $R$. solani (45). However, during our microscopic experiments, we could not observe any effect of phenazines on the growth pattern of $R$. solani. Possibly, the experimental setup did not allow phenazine production to reach concentrations sufficient to inhibit the growth of R. solani.

Biosurfactants can interact with other excreted metabolites, thereby enhancing their bioavailability and bioactivity (9). Along

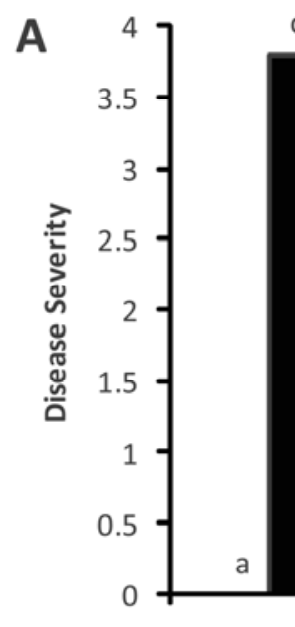

experiment 1

B$$
\text { B }
$$

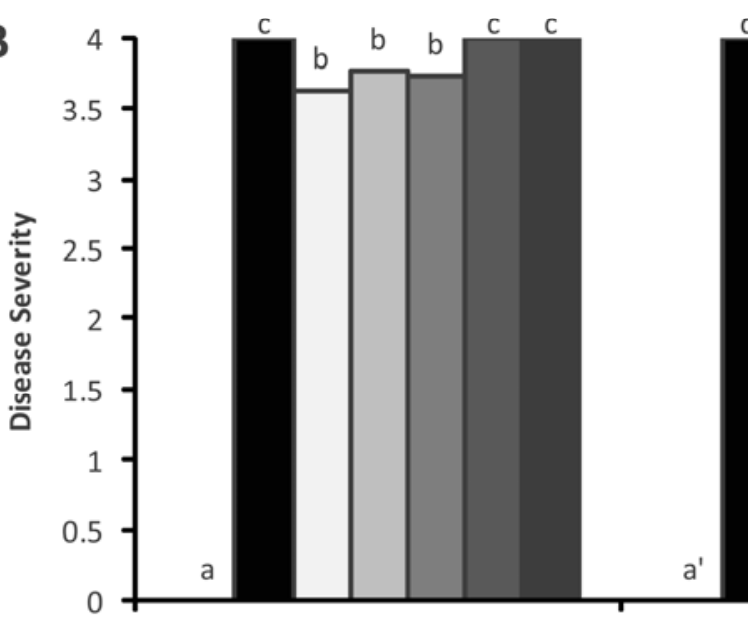

experiment 1

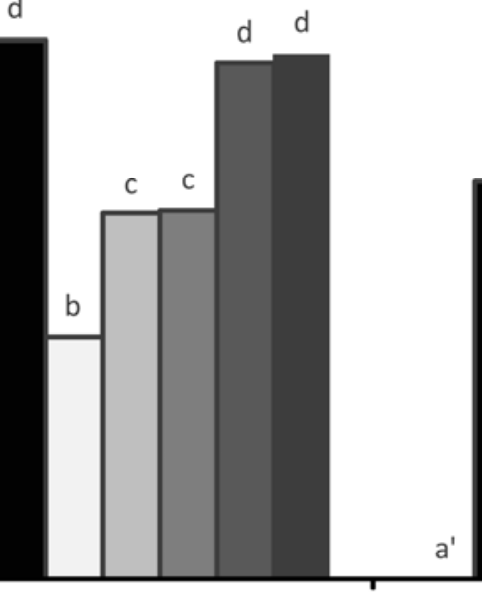

$a^{\prime}$

experiment 2

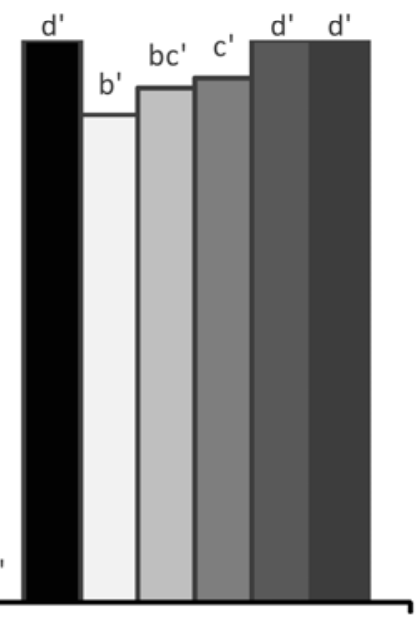

experiment 2

\section{Control}

R. solani

R. solani + CMR12a

R. solani + CMR12a- $\Delta \mathrm{Phz}$

R. solani + CMR12a-CLP1

R. solani + CMR12a- $\triangle$ Phz-CLP1

R. solani + CMR12a-GacA

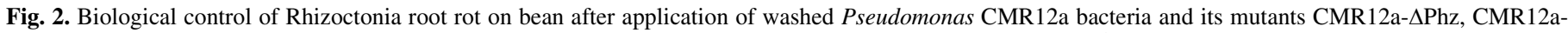

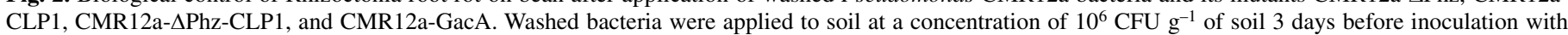

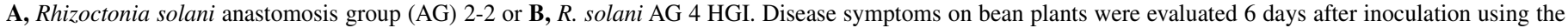

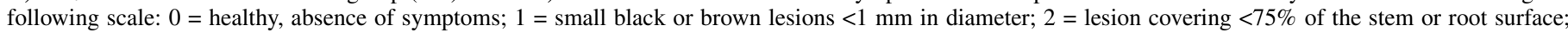

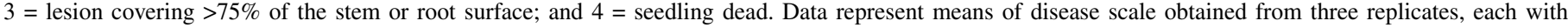

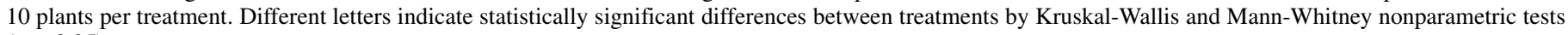
$(\alpha=0.05)$. 
these lines, Perneel et al. (39) showed that simultaneous production of rhamnolipid-type biosurfactants and phenazines is crucial for biological control of Pythium spp. by Pseudomonas aeruginosa PNA1. The authors hypothesized that biosurfactants improved physical contact between hyphae and phenazines and increased entry of phenazines into the fungal cell. In this study, both the CLP-negative mutant CMR12a-CLP1 and the phenazinenegative mutant CMR12a- $\Delta \mathrm{Phz}$ still significantly reduced Rhizoctonia root rot of bean, suggesting an additive effect of CLPs and phenazines. Considering the structural differences between the CLP-type biosurfactants produced by Pseudomonas CMR12a and the rhamnolipid-type biosurfactants produced by $P$. aeruginosa

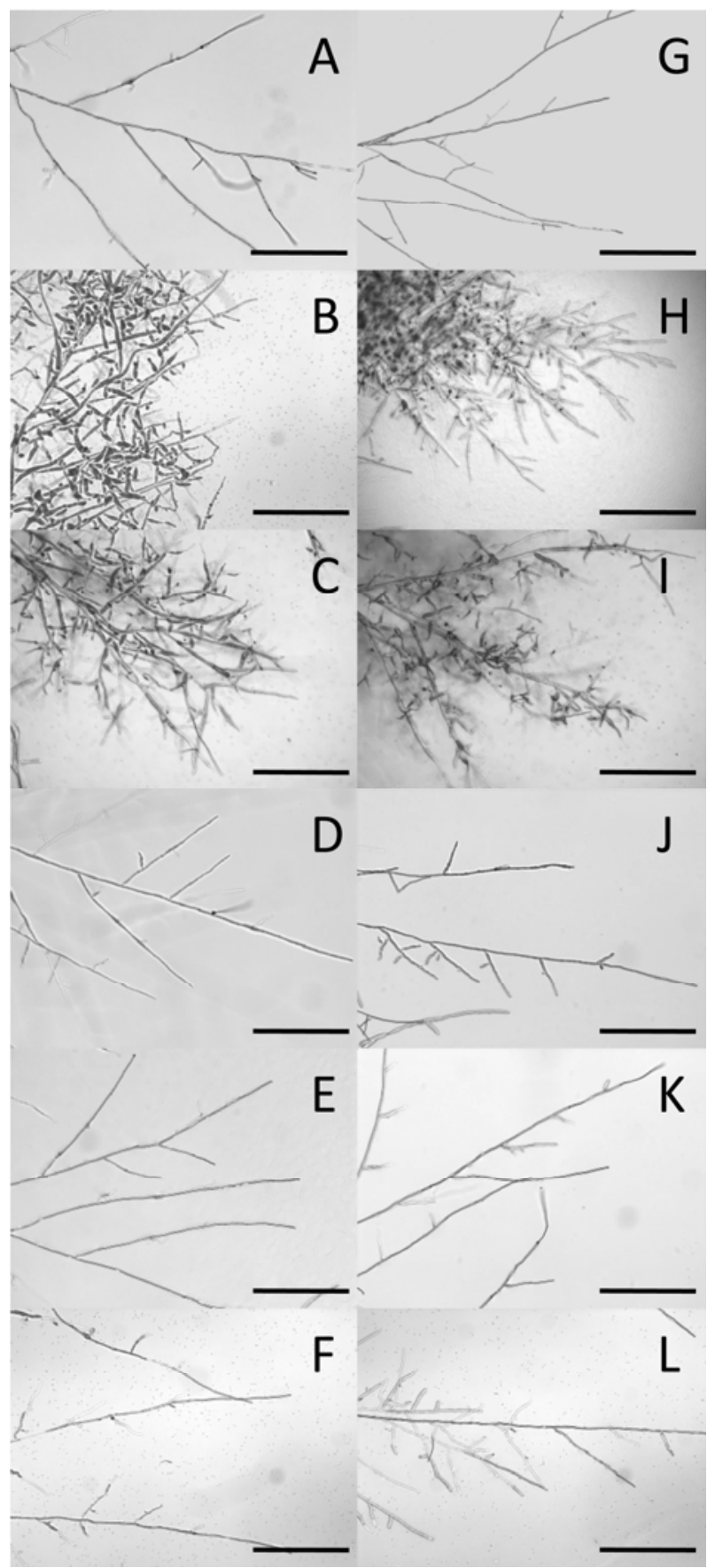

Fig. 3. Mycelial growth pattern of A to F, Rhizoctonia solani anastomosis group (AG) 2-2 and $\mathbf{G}$ to $\mathbf{L}$, AG 4 HGI microscopically observed after different treatments, including $\mathbf{A}$ and $\mathbf{G}$, control; $\mathbf{B}$ and $\mathbf{H}$, Pseudomonas CMR12a; $\mathbf{C}$ and I, Pseudomonas CMR12a- $\Delta \mathrm{Phz}$; $\mathbf{D}$ and $\mathbf{J}$, Pseudomonas CMR12a-CLP1; $\mathbf{E}$ and K, Pseudomonas CMR12a- $\triangle \mathrm{Phz}-\mathrm{CLP1}$; and $\mathbf{F}$ and $\mathbf{L}$, Pseudomonas CMR12a-GacA. Scale bars $=500 \mu \mathrm{m}$.
PNA1, it is reasonable to assume that both groups of biosurfactants have different modes of action (44). However, we cannot exclude the possibility that the second CLP, CLP2, which is still being produced by CMR12a-CLP1 (see above), is involved in enhancing phenazine activity.

Numerous studies have acknowledged the importance of CLPs for bacterial motility and root colonization, which are essential features of bacterial biocontrol agents of soilborne pathogens $(1,39,55,57)$. An increased rhizosphere competence of biosurfactant-producing strains was suggested under sandy soil conditions (36), as were prevalent during the experiments conducted in this study. Phenazine production can provide an additional advantage during establishment in the rhizosphere (31). Consequently, it would not be surprising if phenazines and CLPs produced by CMR12a were involved in the ecological competence of CMR12a. Yet, in this study, root counts of CMR12a$\triangle \mathrm{Phz}$ and CMR12a-CLP1 were not significantly lower in most cases compared with the wild type. Nevertheless, the two mutants deficient in both phenazines and CLPs yielded significantly lower population levels compared with the parental strain, indicating that CMR12a must produce at least one of both compounds to efficiently defend its ecological niche. It must be noted that the gacA mutation in CMR12a-GacA causes pleiotrophic effects, which could influence root colonization and biocontrol capacity for reasons not necessarily related to phenazine or CLP production. Notwithstanding the observed differences in root colonization, all bacterial strains were able to reach a concentration of $10^{5} \mathrm{CFU} \mathrm{\textrm {g } ^ { - 1 }}$ of root, a crucial colonization level considered necessary for optimal biological control $(18,42)$.

An additional important factor influencing the diseasesuppressive effect of CMR12a was the experimental setup; more specifically, preparation of the bacterial inoculum. Application of washed bacteria to soil still had a suppressive effect, although DS was only satisfactorily reduced after infection with $R$. solani AG $2-2$. In the case of the highly aggressive isolate of $R$. solani AG 4 HGI, washed CMR12a bacteria did not provide sufficient protection, and most of the bean plants were killed. Apparently, metabolites produced on $\mathrm{KB}$ plates during growth of the bacteria are important for their biocontrol capacity. These metabolites could provide an advantage to the bacterial cells at the early stages of introduction into soil, preventing a decline in bacterial population generally observed after such an application (3). Nevertheless, bacterial root counts at the evaluation stage did not reveal any significant differences compared with nonwashed bacteria. A follow-up of the bacterial population in time should elucidate whether metabolites produced on plate stimulate rapid root colonization. Furthermore, CMR12a produces signal molecules during growth in vitro, including homoserine lactones that stimulate the production of phenazines (14). Such signal molecules might allow the bacteria to rapidly resume production of phenazines or CLPs once they have colonized the roots.

Together, our results provide evidence for the involvement of phenazines and CLPs in the disease reduction of Rhizoctonia root rot of bean by Pseudomonas CMR12a, and demonstrate the negative impact on biocontrol capacity caused by washing bacteria before soil application. A better insight into the role played by phenazines and biosurfactants in biological control of soilborne pathogens and the regulation and production of these metabolites in situ is imperative for optimization of biological control using Pseudomonas strains.

\section{ACKNOWLEDGMENTS}

J. D'aes and G. K. H. Hua contributed equally to the article. This work was supported by a specialization fellowship of the Flemish Institute for the stimulation of Scientific-Technological Research in Industry (IWT, Belgium) given to J. Pannecoucque and J. D'aes. G. K. H. Hua was given a doctoral grand by the Special Research Fund of the Ghent University. 
Further funding was provided by grants from the Fund for Scientific Research Flanders (FWO grant 3G000210) and the INTERREG IV program France-Wallonie-Vlaanderen (Phytobio project). We thank D. De Vleesschauwer for critically reading the manuscript.

\section{LITERATURE CITED}

1. Andersen, J. B., Koch, B., Nielsen, T. H., Sorensen, D., Hansen, M., Nybroe, O., Christophersen, C., Sorensen, J., Molin, S., and Givskov, M. 2003. Surface motility in Pseudomonas sp DSS73 is required for efficient biological containment of the root-pathogenic microfungi Rhizoctonia solani and Pythium ultimum. Microbiology 149:37-46.

2. Balali, G. R., and Kowsari, A. 2004. Pectic zymogram variation and pathogenicity of Rhizoctonia solani AG-4 to bean (Phaseolus vulgaris) isolates in Isfahn, Iran. Mycopathologia 158:377-384.

3. Bashan, Y. 1998. Inoculants of plant growth-promoting bacteria for use in agriculture. Biotechnol. Adv. 16:729-770.

4. Bolwerk, A., Lagopodi, A. L., Wijfjes, A. H. M., Lamers, G. E. M., ChinA-Woeng, T. F. C., Lugtenberg, B. J. J., and Bloemberg, G. V. 2003. Interactions in the tomato rhizosphere of two Pseudomonas biocontrol strains with the phytopathogenic fungus Fusarium oxysporum f. sp radicis-lycopersici. Mol. Plant-Microbe Interact. 16:983-993.

5. Boyer, H. W., and Roulland-Dussoix, D. 1969. A complementation analysis of the restriction and modification of DNA in Escherichia coli. J. Mol. Biol. 41:459-472.

6. Campion, C., Chatot, C., Perraton, B., and Andrivon, D. 2003. Anastomosis groups, pathogenicity and sensitivity to fungicides of Rhizoctonia solani isolates collected on potato crops in France. Eur. J. Plant Pathol. 109:983-992.

7. Carling, D. E., Kuninaga, S., and Brainard, K. A. 2002. Hyphal anastomosis reactions, rDNA-internal transcribed spacer sequences, and virulence levels among subsets of Rhizoctonia solani anastomosis group-2 (AG-2) and AG-BI. Phytopathology 92:43-50.

8. Chin-A-Woeng, T. F. C., Bloemberg, G. V., van der Bij, A. J., van der Drift, K. M. G. F., Schripsema, J., Kroon, B., Scheffer, R. J., Keel, C., Bakker, P. A. H. M., Tichy, H. V., de Bruijn, F. J., Thomas-Oates, J. E., and Lugtenberg, B. J. J. 1998. Biocontrol by phenazine-1-carboxamideproducing Pseudomonas chlororaphis PCL1391 of tomato root rot caused by Fusarium oxysporum f. sp. radicis-lycopersici. Mol. Plant-Microbe Interact. 11:1069-1077.

9. D'aes, J., De Maeyer, K., Pauwelyn, E., and Hofte, M. 2010. Biosurfactants in plant-Pseudomonas interactions and their importance to biocontrol. Environ. Microbiol. Rep. 2:359-372.

10. Debode, J., De Maeyer, K., Perneel, M., Pannecoucque, J., De Backer, G., and Hofte, M. 2007. Biosurfactants are involved in the biological control of Verticillium microsclerotia by Pseudomonas spp. J. Appl. Microbiol. 103:1184-1196.

11. de Chial, M., Ghysels, B., Beatson, S. A., Geoffroy, V., Meyer, J. M., Pattery, T., Baysse, C., Chablain, P., Parsons, Y. N., Winstanley, C., Cordwell, S. J., and Cornelis, P. 2003. Identification of type II and type III pyoverdine receptors from Pseudomonas aeruginosa. Microbiology 149:821-831.

12. De Jonghe, K., De Dobbelaere, I., Sarrazyn, R., and Hofte, M. 2005. Control of Phytophthora cryptogea in the hydroponic forcing of witloof chicory with the rhamnolipid-based biosurfactant formulation PRO1. Plant Pathol. 54:219-226.

13. De Lorenzo, V., Herrero, M., Jakubzik, U., and Timmis, K. 1990. MiniTn5 transposon derivatives for insertion mutagenesis, promoter probing, and chromosomal insertion of cloned DNA in gram-negative eubacteria. J. Bacteriol. 172:5.

14. De Maeyer, K., D'aes, J., Hua, G. K. H., Perneel, M., Vanhaecke, L., Noppe, H., and Höfte, M. 2011. $N$-acyl homoserine lactone quorum sensing signalling in antagonistic phenazine-producing Pseudomonas isolates from the red cocoyam rhizosphere. Microbiology 157:459-479.

15. de Souza, J. T., de Boer, M., de Waard, P., van Beek, T. A., and Raaijmakers, J. M. 2003. Biochemical, genetic, and zoosporicidal properties of cyclic lipopeptide surfactants produced by Pseudomonas fluorescens. Appl. Environ. Microbiol. 69:7161-7172.

16. Dietrich, L. E. P., Price-Whelan, A., Petersen, A., Whiteley, M., and Newman, D. K. 2006. The phenazine pyocyanin is a terminal signalling factor in the quorum sensing network of Pseudomonas aeruginosa. Mol. Microbiol. 61:1308-1321.

17. Figurski, D. H., and Helinski, D. R. 1979. Replication of an origincontaining derivative of plasmid RK2 dependent on a plasmid function provided in trans. Proc. Natl. Acad. Sci. USA 76:1648-1652.

18. Haas, D., and Defago, G. 2005. Biological control of soil-borne pathogens by fluorescent pseudomonads. Nat. Rev. Microbiol. 3:307-319.

19. Hanahan, D. 1983. Studies on transformation of Escherichia coli with plasmids. J. Mol. Biol. 166:557-580.
20. Handelsman, J., and Stabb, E. V. 1996. Biocontrol of soilborne plant pathogens. Plant Cell 8:1855-1869.

21. Heeb, S., and Haas, D. 2001. Regulatory roles of the GacS/GacA twocomponent system in plant-associated and other gram-negative bacteria. Mol. Plant-Microbe Interact. 14:1351-1363.

22. Herrero, M., Delorenzo, V., and Timmis, K. N. 1990. Transposon vectors containing non-antibiotic resistance selection markers for cloning and stable chromosomal insertion of foreign genes in gram-negative bacteria. J. Bacteriol. 172:6557-6567.

23. Hoang, T. T., Karkhoff-Schweizer, R. R., Kutchma, A. J., and Schweizer, H. P. 1998. A broad-host-range Flp-FRT recombination system for sitespecific excision of chromosomally-located DNA sequences: application for isolation of unmarked Pseudomonas aeruginosa mutants. Gene 212:77-86

24. Howell, C. R., and Stipanovic, R. D. 1979. Control of Rhizoctonia solani on cotton seedlings with Pseudomonas fluorescens and with an antibiotic produced by the bacterium. Phytopathology 69:480-482.

25. Huang, Z. Y., Bonsall, R. F., Mavrodi, D. V., Weller, D. M., and Thomashow, L. S. 2004. Transformation of Pseudomonas fluorescens with genes for biosynthesis of phenazine-1-carboxylic acid improves biocontrol of Rhizoctonia root rot and in situ antibiotic production. FEMS Microbiol. Ecol. 49:243-251.

26. Jain, D. K., Collinsthompson, D. L., Lee, H., and Trevors, J. T. 1991. A drop-collapsing test for screening surfactant-producing microorganisms. J. Microbiol. Methods 13:271-279.

27. Kataria, H. R., and Gisi, U. 1996. Chemical control of Rhizoctonia species. In: Rhizoctonia Species: Taxonomy, Molecular Biology, Ecology, Pathology and Disease Control. B. Sneh, S. Jabaji-Hare, S. M. Neate, and G. Dijst, eds. Kluwer Academic, Dordrecht, The Netherlands.

28. King, E. O., Ward, M. K., and Raney, D. E. 1954. Two simple media for the demonstration of pyocyanin and fluorescein. J. Lab. Clin. Med. 44:301-307.

29. Kloepper, J. W., Ryu, C. M., and Zhang, S. A. 2004. Induced systemic resistance and promotion of plant growth by Bacillus spp. Phytopathology 94:1259-1266.

30. Mavrodi, D. V., Peever, T. L., Mavrodi, O. V., Parejko, J. A., Raaijmakers, J. M., Lemanceau, P., Mazurier, S., Heide, L., Blankenfeldt, W., Weller, D. M., and Thomashow, L. S. 2010. Diversity and evolution of the phenazine biosynthesis pathway. Appl. Environ. Microbiol. 76:866-879.

31. Mazzola, M., Cook, R. J., Thomashow, L. S., Weller, D. M., and Pierson, L. S. 1992. Contribution of phenazine antibiotic biosynthesis to the ecological competence of fluorescent pseudomonads in soil habitats. Appl. Environ. Microbiol. 58:2616-2624.

32. Muyolo, N. G., Lipps, P. E., and Schmitthenner, A. F. 1993. Anastomosis grouping and variation in virulence among isolates of Rhizoctonia solani associated with dry bean and soybean in Ohio and Zaire. Phytopathology $83: 438-444$.

33. Nandakumar, R., Babu, S., Viswanathan, R., Raguchander, T., and Samiyappan, R. 2001. Induction of systemic resistance in rice against sheath blight disease by Pseudomonas fluorescens. Soil Biol. Biochem. 33:603-612.

34. Nerey, Y., Pannecoucque, J., Hernandez, H. P., Diaz, M., Espinosa, R., De Vos, S., Van Beneden, S., Herrera, L., and Hofte, M. Rhizoctonia spp. causing root and hypocotyl rot in Phaseolus vulgaris in Cuba. J. Phytopathol. 158:236-243.

35. Nielsen, T. H., Christophersen, C., Anthoni, U., and Sorensen, J. 1999. Viscosinamide, a new cyclic depsipeptide with surfactant and antifungal properties produced by Pseudomonas fluorescens DR54. J. Appl. Microbiol. 87:80-90.

36. Nielsen, T. H., Sorensen, D., Tobiasen, C., Andersen, J. B., Christophersen, C., Givskov, M., and Sorensen, J. 2002. Antibiotic and biosurfactant properties of cyclic lipopeptides produced by fluorescent Pseudomonas spp. from the sugar beet rhizosphere. Appl. Environ. Microbiol. 68:3416-3423.

37. Nielsen, T. H., Thrane, C., Christophersen, C., Anthoni, U., and Sorensen, J. 2000. Structure, production characteristics and fungal antagonism of tensin-a new antifungal cyclic lipopeptide from Pseudomonas fluorescens strain 96.578. J. Appl. Microbiol. 89:992-1001.

38. Pattery, T., Hernalsteens, J. P., and De Greve, H. 1999. Identification and molecular characterization of a novel Salmonella enteritidis pathogenicity islet encoding an ABC transporter. Mol. Microbiol. 33:791-805.

39. Perneel, M., D'Hondt, L., De Maeyer, K., Adiobo, A., Rabaey, K., and Hofte, M. 2008. Phenazines and biosurfactants interact in the biological control of soil-borne diseases caused by Pythium spp. Environ. Microbiol. 10:778-788

40. Perneel, M., Heyrman, J., Adiobo, A., De Maeyer, K., Raaijmakers, J. M., De Vos, P., and Hofte, M. 2007. Characterization of CMR5c and CMR12a, novel fluorescent Pseudomonas strains from the cocoyam rhizosphere with biocontrol activity. J. Appl. Microbiol. 103:1007-1020.

41. Pham, T. H., Boon, N., Aelterman, P., Clauwaert, P., De Schamphelaire, 
L., Vanhaecke, L., De Maeyer, K., Hofte, M., Verstraete, W., and Rabaey, K. 2008. Metabolites produced by Pseudomonas spp. enable a grampositive bacterium to achieve extracellular electron transfer. Appl. Microbiol. Biotechnol. 77:1119-1129.

42. Raaijmakers, J. M., Bonsall, R. E., and Weller, D. M. 1999. Effect of population density of Pseudomonas fluorescens on production of 2,4diacetylphloroglucinol in the rhizosphere of wheat. Phytopathology 89:470-475.

43. Raaijmakers, J. M., de Bruijn, I., and de Kock, M. J. D. 2006. Cyclic lipopeptide production by plant-associated Pseudomonas spp.: diversity, activity, biosynthesis, and regulation. Mol. Plant-Microbe Interact. 19:699-710.

44. Ron, E. Z., and Rosenberg, E. 2001. Natural roles of biosurfactants. Environ. Microbiol. 3:229-236.

45. Rosales, A. M., Thomashow, L., Cook, R. J., and Mew, T. W. 1995. Isolation and identification of antifungal metabolites produced by riceassociated antagonistic Pseudomonas spp. Phytopathology 85:1028-1032.

46. Sambrook, J., Fritsch, E. F., and Maniatis, T. 1989. Molecular Cloning: A Laboratory Manual, second edition. Cold Spring Harbor Laboratory Press, Cold Spring Harbor, NY.

47. Scholten, O. E., Panella, L. W., De Bock, T. S. M., and Lange, W. 2001. A greenhouse test for screening sugar beet (Beta vulgaris) for resistance to Rhizoctonia solani. Eur. J. Plant Pathol. 107:161-166.

48. Schweizer, H. P. 1993. Small broad-host-range gentamicin resistance gene cassettes for site-specific insertion and deletion mutagenesis. Biotechniques 15:831-833.

49. Shanks, R. M. Q., Caiazza, N. C., Hinsa, S. M., Toutain, C. M., and O'Toole, G. A. 2006. Saccharomyces cerevisiae-based molecular tool kit for manipulation of genes from gram-negative bacteria. Appl. Environ.
Microbiol. 72:5027-5036

50. Stanghellini, M. E., and Miller, R. M. 1997. Biosurfactants: their identity and potential efficacy in the biological control of zoosporic plant pathogens. Plant Dis. 81:4-12.

51. Tambong, J. T., and Hofte, M. 2001. Phenazines are involved in biocontrol of Pythium myriotylum on cocoyam by Pseudomonas aeruginosa PNA1. Eur. J. Plant Pathol. 107:511-521.

52. Thomashow, L. S., and Weller, D. M. 1988. Role of a phenazine antibiotic from Pseudomonas fluorescens in biological control of Gaeumannomyces graminis var. tritici. J. Bacteriol. 170:3499-3508.

53. Thrane, C., Nielsen, M. N., Sorensen, J., and Olsson, S. 2001. Pseudomonas fluorescens DR54 reduces sclerotia formation, biomass development, and disease incidence of Rhizoctonia solani causing damping-off in sugar beet. Microb. Ecol. 42:438-445.

54. Thrane, C., Olsson, S., Nielsen, T. H., and Sorensen, J. 1999. Vital fluorescent stains for detection of stress in Pythium ultimum and Rhizoctonia solani challenged with viscosinamide from Pseudomonas fluorescens DR54. FEMS Microbiol. Ecol. 30:11-23.

55. Tran, H., Ficke, A., Asiimwe, T., Hofte, M., and Raaijmakers, J. M. 2007. Role of the cyclic lipopeptide massetolide A in biological control of Phytophthora infestans and in colonization of tomato plants by Pseudomonas fluorescens. New Phytol. 175:731-742.

56. Turner, J. M., and Messenger, A. J. 1986. Occurrence, biochemistry and physiology of phenazine pigment production. Adv. Microb. Physiol. 27:211-275.

57. Weller, D. M. 1988. Biological control of soilborne plant pathogens in the rhizosphere with bacteria. Annu. Rev. Phytopathol. 26:379-407.

58. Weller, D. M. 2007. Pseudomonas biocontrol agents of soilborne pathogens: Looking back over 30 years. Phytopathology 97:250-256. 